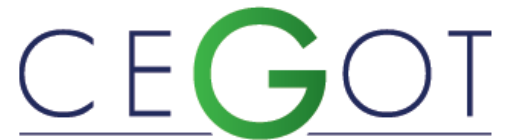

Centro de Estudos de Geografia e Ordenamento do Território
Geografia e Ordenamento do Território, Revista Eletrónica Centro de Estudos de Geografia e Ordenamento do Território http://cegot.org SOUZA, SÉRGIO

Instituto Federal de Brasília - IFB, Campus Ceilândia

QNN 26, área especial, CEP 72.220-260, Ceilândia, Brasília-DF, Brasil smcsgeo@gmail.com

\title{
Análise da evolução recente da densidade de empregos na Região Integrada de Desenvolvimento do Distrito Federal e Entorno (Ride-DF)
}

Analysis of the recent evolution of employment density in the Integrated Region of Development of Brasília (Ride-DF)

Referência: Souza, Sérgio (2018). Análise da evolução recente da densidade de empregos na Região Integrada de Desenvolvimento do Distrito Federal e Entorno (Ride-DF). Revista de Geografia e Ordenamento do Território (GOT), n. ${ }^{\circ} 14$ (setembro). Centro de Estudos de Geografia e Ordenamento do Território, p. 333-358, dx.doi.org/10.17127/got/2018.14.014

\section{RESUMO}

O processo de reestruturação produtiva capitalista tem levado a uma reorganização espacial da economia, impondo novos processos responsáveis pela produção dos espaços regionais. No caso específico da Região Integrada de Desenvolvimento do Distrito Federal e Entorno (Ride-DF), tal tendência é manifestada pela atuação dos processos de expansão da agropecuária moderna e integração do Eixo Brasília-Anápolis-Goiânia. O objetivo deste trabalho é analisar a evolução recente da densidade de empregos na Ride-DF, com o objetivo de identificar possíveis efeitos do processo de reestruturação produtiva na região, além de possíveis efeitos da atual crise econômica na estrutura econômica da região em estudo. Os resultados indicam maior densidade de empregos na área de atuação dos dois processos citados, e reduzida densidade nos municípios periféricos afetados por outro processo estruturador da Ride-DF: a expansão metropolitana de Brasília.

Palavras-chave: Ride-DF; densidade de empregos; reestruturação produtiva; regiões e desenvolvimento regional

\section{ABSTRACT}

The capitalist productive restructuring process has led to a reorganization of the spatial economy, by imposing new process responsible for the production of the regional spaces. Regarding the Integrated Region of Development of Brasilia (Ride-DF), this tendency is manifested by the action of the modern agriculture expansion process and the integration of the axis Brasilia-Anapolis-Goiania. This work aims to analyse the recent evolution of the employment density in the Ride-DF, seeking to identify possible effects of the productive restructuring process in this region, as well as possible effects of the current economic crisis on the economic structure of the region under study. The results points to a major density of employment in the area of actuation of the two mentioned process and reduced density 
in the peripheral municipalities affected by the other structuring process of the Ride-DF: the metropolitan expansion of Brasilia.

Keywords: Ride-DF; employment density; productive restructuring; regions and regional development.

\section{Introdução}

O processo de reestruturação produtiva do capitalismo tem sido responsável por alterações na estrutura econômica dos espaços metropolitanos e regionais e, no caso de Brasília, tal tendência tem se manifestado a partir da incidência de três macroprocessos responsáveis pela produção de seu espaço metropolitano e regional: a expansão metropolitana de Brasília, a expansão da agropecuária moderna ${ }^{1}$ e a integração do Eixo Brasília-AnápolisGoiânia. Este trabalho busca compreender modificações recentes na estrutura econômica da Região Integrada de Desenvolvimento do Distrito Federal e Entorno (Ride-DF), espaço que delimita o espaço de influência metropolitano e regional de Brasília.

No contexto de reestruturação produtiva, tem aumentado a fragmentação e consequente heterogeneidade nos espaços metropolitanos e regionais. Na escala regional, trabalhos como o de Santos (1996) apontam para a interferência dos agentes externos sobre regiões particulares, na ideia das verticalidades e horizontralidades; Veltz (1996), ao abordar o novo formato da economia no espaço a enuncia como sendo de "arquipélagos", nos quais há uma organização menos contínua dos espaços produtivos; Allen et al (1998) abordam tais heterogeneidades a partir das múltiplas relações sociais estabelecidas nos espaços regionais. Na escala metropolitana tem-se verificado uma clara mudança em sua estrutura econômica, na qual há manutenção das atividades terciárias e dispersão das atividades produtivas, traduzindo-se em um novo padrão de localização dos empregos. Gordon e

\footnotetext{
${ }^{1}$ Por "agropecuária moderna" entende-se aquela que é resultado da associação do capital, especialmente da alta finança, com a produção no setor primário da economia, integrando a este setor outros setores produtivos (como a indústria). No caso brasileiro, tal formato surge a partir da década de 1960, com a reorganização do sistema de crédito agrícola nacional (GRAZIANO DA SILVA, 1996). Deu-se preferência ao uso dessa terminologia em contraste com a ideia de agronegócio, mais corrente, pois esta, por vezes, padece de uma definição pouco precisa: agronegócio, de forma objetiva, não obrigatoriamente refere-se aos grandes produtores. A ideia de uma agropecuária moderna é aquela na qual não há apenas a mecanização, mas também a integração a um sistema financeiro (a um circuito ampliado) e produtivo maior, em geral de produtores mais capitalizados.
} 
Richardson (1996) chegaram a teorizar a possibilidade de que a formação de subcentros seria o passo intermediário para uma realidade de empregos dispersos e sem padrão definido de localização. Garcia-López e Muñiz (2010), testando tal hipótese para o caso de Barcelona, apontaram que ambos os processos coincidem, dispersão e reconcentração de empregos em subcentros, não havendo a tendência a uma dispersão absoluta e sem estrutura dos empregos urbanos e metropolitanos. Analisando o caso alemão e a partir de metodologia baseada na ideia da rede de cidades globais, Münter (2011) verifica que nos principais centros, especialmente os de consolidação mais antiga (chamado de modelo suburbano) e que perfazem a típica trajetória pós-fordista, há um padrão de policentrismo, porém com o centro principal mantendo as principais ligações com os centros globais. Mais proximamente, para o caso latino-americano, outros agentes são arrolados como promotores de tal processo de dispersão dos empregos, especificamente o setor imobiliário, que primeiramente aumenta o tecido urbano e, com o tempo, leva ao surgimento de nucleações de atividades, na análise de Heinrichs et al (2009).

No caso específico da Ride-DF, tal situação tem sido verificada mais recentemente. Esta região, delimitada por meio da Lei Complementar no 94/1998, compreende a extensão do fenômeno metropolitano de Brasília e uma parte de sua área de influência regional, sendo utilizada na aplicação de políticas públicas pelas diferentes esferas de governo. Sobre tal espaço, Queiroz (2007) apontou, anteriormente, para a sua característica heterogênea em torno do histórico, da paisagem e das funções de seus municípios. Mais recentemente, Souza $(2016 ; 2017$ a) apontou conclusões que reforçam tal fragmentação e a emergência de novos processos nesta região. Em Souza (2016), foi utilizado como um dos indicadores da identificação das centralidades na Ride-DF uma análise da densidade de empregos face à população residente nos municípios, tendo como base os dados da Relação Anual de Informações Sociais do Ministério do Trabalho (RAIS), para 2014, e do Censo 2010. Com a divulgação recente dos dados da RAIS para 2015 e 2016, bem como com as estimativas de população do IBGE para os municípios, torna-se relevante rever os cálculos realizados anteriormente, além de apresentá-los para anos mais recentes. Para além da simples atualização e revisão dos dados, o cálculo da densidade de empregos é fundamental por ao menos três motivos: atualiza a compreensão do processo de modificação da estrutura econômica da metrópole de Brasília e da Ride-DF; subsidia novos rumos para a gestão deste 
território, em claro processo de modificação; permite avaliar, na escala regional e metropolitana, possíveis efeitos da atual crise econômica brasileira.

Desta forma, o objetivo deste trabalho é analisar a evolução recente da densidade de empregos na Ride-DF a partir dos dados da RAIS e da estimativa de população do IBGE, com o fim de analisar possíveis efeitos do processo de reestruturação produtiva na região, bem como possíveis efeitos da atual crise econômica na estrutura econômica da região em estudo.

O trabalho encontra-se estruturado da seguinte forma: na próxima seção é apresentada a evolução histórica da produção do espaço da região de Brasília até sua "oficialização" por meio da Ride-DF; em seguida é descrita e brevemente discutida a metodologia utilizada para analisar os dados, especialmente em torno das medidas de análise de densidade de empregos como indicador de centralidade; depois são apresentados os resultados e sua discussão; por fim seguem as considerações finais.

\section{Uma breve análise da evolução da produção do espaço da Ride-DF}

A evolução da produção do espaço da Ride-DF pode ser compreendida a partir de uma periodização na qual sejam enfatizados, principalmente, os principais processos responsáveis pela produção deste espaço regional. Neste sentido, considerando que a RideDF seria a "região oficial" de Brasília (ainda que em certo sentido, especialmente jurídicolegal, ela seja tratada como espaço metropolitano de Brasília), a análise de sua evolução tem como ponto de partida justamente o início do processo de construção de Brasília. Obviamente, como a Ride-DF foi institucionalizada apenas em 1998, a referência neste período anterior se faz ao espaço que hoje corresponde à Ride-DF e que esteve contida em outras regionalizações, como a Região Geoeconômica de Brasília².

\footnotetext{
${ }^{2}$ A linha de evolução da produção do espaço da Ride-DF aqui utilizada é baseada, com algumas alterações, na adotada em Souza (2016). Contrariamente a este trabalho, o presente enfoca mais os processos responsáveis pela produção do espaço da Ride-DF, e menos a delimitação específica de cada período.
} 
A primeira etapa, marcada pela implantação de Brasília ocorreu no contexto de integração e modernização do território nacional, nas décadas de 1950 e 1960, tendo ocorrido em região onde predominava uma agricultura pouco mecanizada, voltada à subsistência. As ações de gestão do território estiveram mais ligadas ao imperativo de construção da nova capital e ao planejamento urbano daí decorrente, com pouca atenção dispensada à questão regional ${ }^{3}$. Como desdobramento das ações de gestão do território, houve a implantação da capital, porém em moldes diferentes do previsto em seu plano urbanístico, dada a criação das primeiras cidades-satélites. O conjunto destas e do centro principal, do qual dependiam fundamentalmente, levaram à criação de um espaço polinucleado, segundo Paviani (1987). Numa escala regional, os desdobramentos principais deram-se no desmembramento de municípios e no surgimento, em alguns deles, de novos espaços de assentamento, porém sem o caractere metropolitano da etapa seguinte.

Numa segunda etapa, datada entre as décadas de 1970 e 1980, os processos de maior importância serão a formação da Brasília metrópole e sua expansão inicial e a implantação da agropecuária moderna. Isto se deu no contexto de consolidação de Brasília como capital federal e de inclusão do Centro-Oeste brasileiro como espaço produtivo da agropecuária. Em tal contexto, as ações de gestão do território passam a dar maior ênfase à questão regional, atuando no espaço em questão dois programas (entre outros), decorrentes do II Plano Nacional de Desenvolvimento (1975): o Programa Especial da Região Geoeconômica de Brasília (Pergeb), que pressupunha uma atuação em torno do controle da intensa imigração para a Nova Capital, por meio de ações de desenvolvimento nos municípios vizinhos (e em uma escala regional mais ampla); e o Programa de Desenvolvimento de Cerrados (Polocentro), que continha ações justamente de inclusão do Centro-Oeste no quadro produtivo nacional, especialmente no setor agrícola modernizado. Em âmbito urbano, as ações de gestão do território estiveram mais ligadas à busca do controle da expansão urbana, o que levou à criação de novas cidades-satélites e ao estímulo às emigrações do Distrito Federal para os municípios do Entorno de Brasília (dada a política de forte controle do acesso à terra praticada pelo Governo do Distrito Federal). Como desdobramentos destas ações, a expansão urbana de Brasília torna-se expansão

\footnotetext{
${ }^{3}$ Como ação de âmbito regional houve a criação do Fundo de Desenvolvimento do Distrito Federal (Fundefe), cuja atuação não se deu articulada à instrumentos de planejamento regional (FREITAG, 2012).
} 
metropolitana, ao atingir os municípios vizinhos ao Distrito Federal. Em escala regional, como efeito principalmente do Polocentro, ocorreu a implantação da agropecuária moderna, principalmente nos municípios de Formosa e Unaí.

Na terceira e mais recente etapa, a partir da década de 1990, passa a ocorrer a atuação dos atuais três macroprocessos estruturantes deste espaço regional: a expansão metropolitana de Brasília; a expansão da agropecuária moderna; a integração do eixo Brasília-AnápolisGoiânia. A atuação destes processos tem ocorrido em um contexto de maior integração da economia brasileira à globalização, com a consequente reestruturação dos espaços produtivos e a adoção de um modelo de atuação do Estado calcado no neoliberalismo ${ }^{4}$. Em tal contexto, as ações específicas na Região de Brasília em torno das políticas regionais apontam, num primeiro momento, para a formalização de uma "região oficial" de Brasília, a Ride-DF. Tal formalização ocorreu ainda no contexto da discussão sobre a formalização de um espaço metropolitano para Brasília, a partir de estudo da Codeplan (1997). Tal estudo previa uma menor quantidade de municípios para tal espaço, sendo que ao final acabou prevalecendo uma delimitação que abarcou municípios sem integração metropolitana com Brasília (Lei Complementar no 94/1998). Assim, a Ride-DF acaba por possuir um caráter híbrido, meio caminho entre o espaço metropolitano de Brasília e seu espaço de influência regional. A Figura 1 apresenta o mapa com a composição destes municípios ${ }^{5}$.

A formalização da Ride-DF, contudo, não levou a uma efetiva ação de gestão do território nem em âmbito metropolitano, nem em âmbito regional. Tendo seu Conselho Administrativo atualmente abrigado na estrutura da Superintendência do Desenvolvimento

\footnotetext{
4 "Neoliberalismo" é compreendido neste trabalho como sendo o resultado do atual modelo de regulação (ou desregulação) da economia capitalista, baseado na premissa de um Estado com reduzida capacidade de intervenção e maior protagonismo de agentes privados. Além desta definição, mais comum, adota-se a perspectiva proposta por Dardot e Laval (2016), no qual o neoliberalismo, mais do que um regime regulatório, torna-se a própria premissa da sociedade contemporânea, na qual a competitividade desce ao nível claro do individual (não mais restrito às organizações) e se torna o novo natural.

${ }^{5}$ Compõem a Ride-DF, além do Distrito Federal, os seguintes municípios: Abadiânia, Água Fria de Goiás, Águas Lindas, Alexânia, Cabeceiras, Cidade Ocidental, Cocalzinho de Goiás, Corumbá de Goiás, Cristalina, Formosa, Luziânia, Mimoso de Goiás, Novo Gama, Padre Bernardo, Pirenópolis, Planaltina, Santo Antônio do Descoberto, Valparaíso e Vila Boa, no Estado de Goiás, e de Unaí e Buritis, no Estado de Minas Gerais. Sobre Cabeceira Grande-MG, a posição atual da Superintendência do Desenvolvimento do Centro-Oeste (SUDECO) é de este, por ter sido criado antes da edição da Lei Complementar no 94/1998, não pertence legalmente à RideDF. Neste trabalho, entretanto, tal município será considerado como pertencente à região, já que a própria composição do mapa dos municípios revela a existência de erro no conteúdo da legislação (o que deverá ser corrigido futuramente, haja vista a existência de projetos de lei que visam incluir Cabeceira Grande na região).
} 
do Centro-Oeste (Sudeco), as ações de planejamento são inexistentes (ao menos com abrangência para toda a região) e as intervenções muito pontuais, visando atender interesses políticos pulverizados, ou por meio dos fundos de fomento regionais, como o Fundo Constitucional de Financiamento do Centro-Oeste (FCO), cujos recursos destinam-se ao setor produtivo.

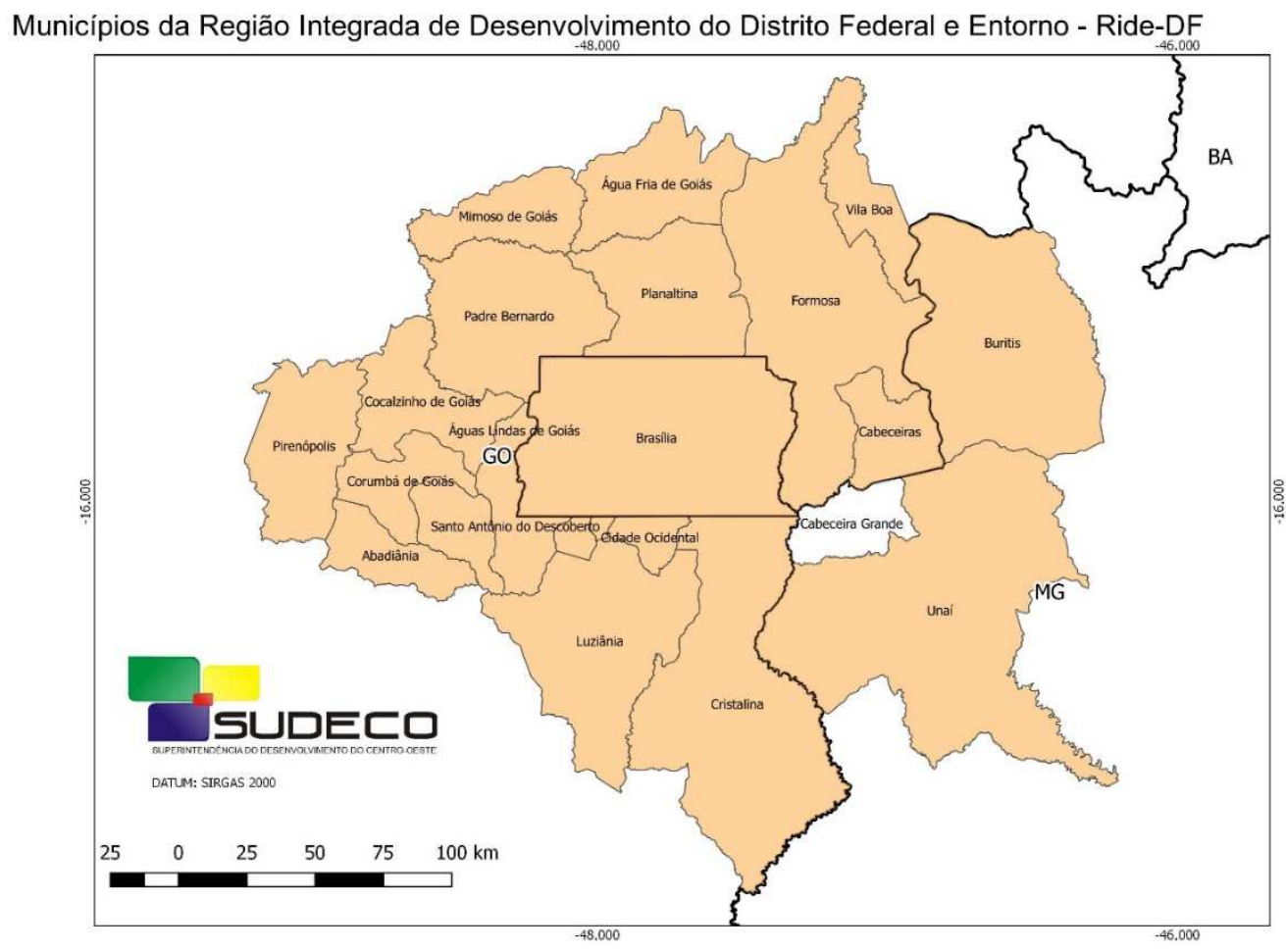

Figura 1 - Municípios integrantes da Ride-DF (Fonte: SUDECO, 2018)

A partir destas ações, os principais desdobramentos apontam para a ocorrência dos três macroprocessos anteriormente mencionados como sendo os responsáveis pela produção do espaço da Ride-DF. A expansão metropolitana de Brasília é continuidade da primeira expansão iniciada na década de 1970, porém com novos eixos de expansão: ao sul, sobre o território de Luziânia (que se desmembrou em outros municípios); à oeste, em direção à Águas Lindas de Goiás; à norte, rumo à Planaltina. Estes novos braços têm como espinha dorsal os principais eixos rodoviários do Distrito Federal, e tem como estímulo, no momento atual, políticas de acesso à moradia por meio de crédito mais barato, como o Programa Minha Casa Minha Vida (PMCMV). O segundo macroprocesso, a expansão da agropecuária moderna, é consequência da manutenção da atuação do Estado em favor do setor produtivo agrícola que, a partir da década de 1990, inicia um processo de expansão para 
além dos primeiros municípios afetados pela implantação da modernização no campo. Os principais alvos de tal processo são os municípios ao leste do Distrito Federal, formando o que foi anteriormente chamado de "arco da agropecuária moderna" (SOUZA, 2016). Por fim, em função da consolidação das economias voltadas aos serviços de Goiânia e Brasília e da consolidação de Anápolis como polo produtor do secundário e importante nó logístico do Centro-Oeste brasileiro, tem emergido o terceiro macroprocesso, a integração econômica e funcional do eixo entre estas três cidades, em torno da BR 060 (MIRAGAYA, 2003).

Descritos os três macroprocessos, é possível resgatar a tipologia proposta por Souza (2016) para os municípios da Ride-DF, que dará base às análises da densidade de empregos. Tal tipologia (ou regionalização), bem como a área de atuação dos três macroprocessos encontra-se representada na Figura 2. Assim, os municípios foram divididos da seguinte forma:

- Centro metropolitano e espaço metropolizado: correspondem ao Distrito Federal e ao espaço já alcançado pela expansão metropolitana de Brasília;

- Área de influências combinadas: corresponde ao município de Luziânia, no qual há presença da atuação tanto da expansão metropolitana quanto da expansão da agropecuária moderna;

- Arco da agropecuária moderna: espaço no qual as atividades da agropecuária moderna têm desenvolvido suas atividades;

- Eixo Brasília-Anápolis-Goiânia: corresponde aos municípios de Abadiânia e Alexânia, onde novas atividades estão surgindo em função da integração econômica das capitais federal e goiana;

- Agropecuária tradicional: municípios nos quais o desenvolvimento de atividades mais modernas na agropecuária é ainda reduzido; e

- Área do turismo: corresponde à Pirenópolis, local onde esta atividade tem notório destaque.

Tal mapeamento dos processos e das subregionalizações por eles geradas é, como dito, resultado do processo de reestruturação produtiva na Ride-DF e da manutenção de Brasília como metrópole terciária. Para chegar a tal tipologia, um dos passos seguidos foi a identificação dos subcentros nesta região, realizada no já mencionado trabalho de Souza (2016). Para tanto, um dos componentes do indicador de centralidade elaborado dizia 
respeito justamente à densidade de empregos. Tendo em vista a existência de dados mais atualizados que os então utilizados, além da mudança na base demográfica considerada, é possível vislumbrar alterações mais recentes no quadro da densidade de empregos, além de possíveis efeitos da atual crise econômica. Antes de adentrar especificamente nesta análise, a próxima seção apresenta a metodologia utilizada (e sua discussão).

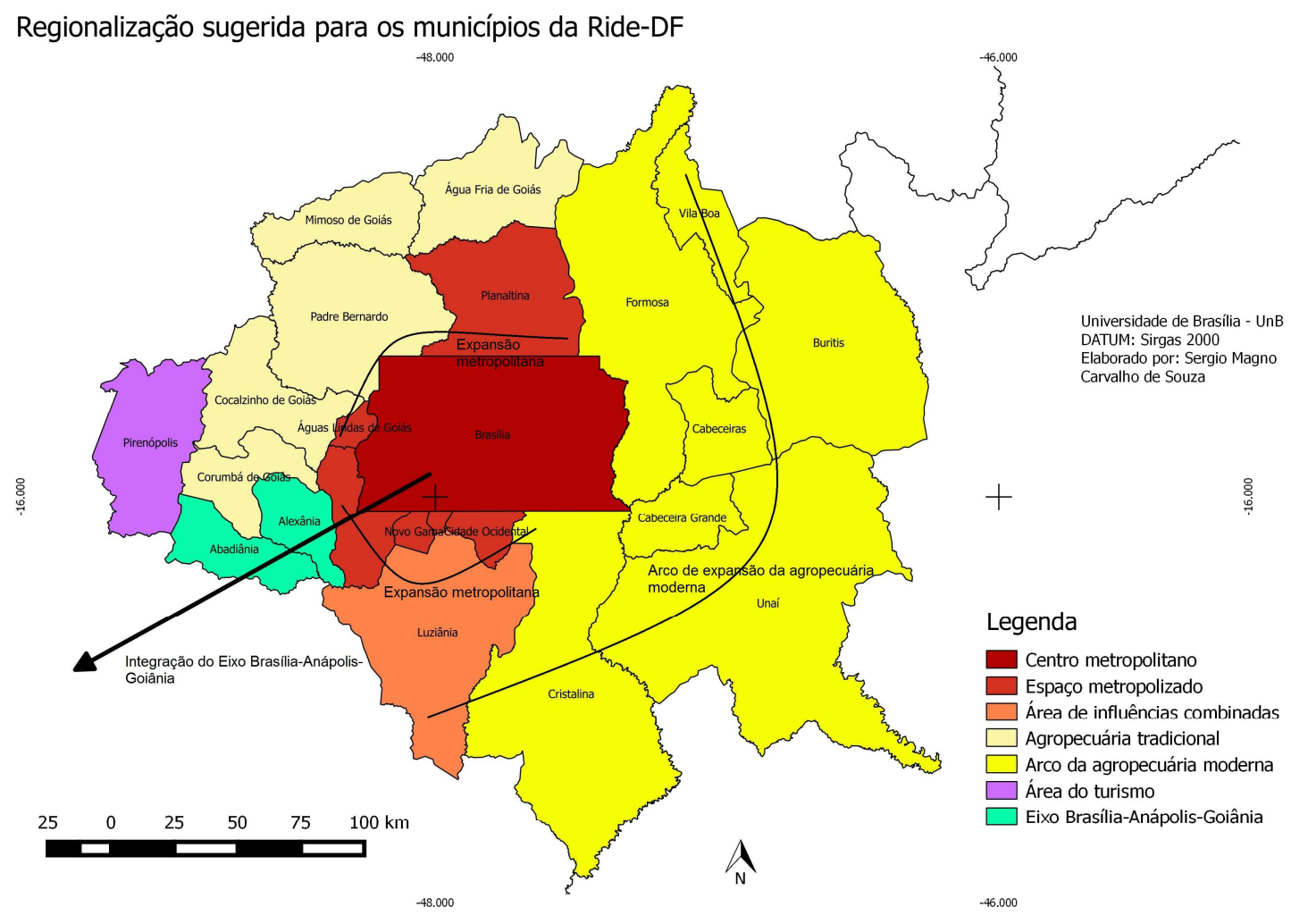

Figura 2 - Regionalização proposta para os municípios da Ride-DF (Fonte: SOUZA, 2016)

\section{Metodologia}

As formas de identificação de subcentros em escala regional tem variado no tempo, constituindo-se preocupação importante de disciplinas como a Geografia e a Economia Regional. Para tanto, diversas métricas e modelos têm sido utilizados a partir de variados critérios.

Alguns dos estudiosos do tema dão maior importância à identificação dos subcentros regionais em perspetiva qualitativa, relevando o papel dos fluxos existentes e da funcionalidade dos empregos existentes. Destaca-se o trabalho de Bourne (1989), que 
propõe como metodologia de identificação dos subcentros critérios como a medição da distância do trabalho para casa e o destino dos fluxos de trabalho. Nigriello et al (2002) propõem a identificação de pontos de articulação, a partir da análise dos fluxos urbanos e regionais. Mignot e Aguiléra (2004) consideram a importância da polarização, por meio da análise dos fluxos, na delimitação dos subcentros, sendo indicadores a quantidade de pessoas que estudam e trabalham em municípios vizinhos. Vale ainda lembrar que o IBGE utiliza critérios próximos a este na definição da hierarquia urbana e da região de influência dos centros urbanos, considerando, nas últimas pesquisas, o peso da gestão do território realizado por um determinado centro urbano (IBGE, 2008).

Outros estudiosos do tema têm proposto a análise dos subcentros a partir da concentração/ densidade dos empregos existentes, a partir de métricas especificas. Neste espectro, é bastante conhecido o trabalho de Giuliano e Small (1991) que aplicaram seu modelo ao estudo do caso de Los Angeles. Eles trabalham com dois critérios: cada zona deveria ter uma densidade mínima (por área) de empregos e um percentual fixo do total de empregos. McDonald (1987) introduziu neste mesmo sentido, a análise da contiguidade, sendo delimitado como subcentro uma zona na qual os indicadores sejam maiores que nos vizinhos.

Destes estudos, o presente trabalho se filia ao segundo grupo, tendo a metodologia empregada inspiração no trabalho de Duarte et al (2010). Trabalhando com o caso de cidades espanholas (entre elas Madrid e Barcelona), um dos indicadores dizia respeito à densidade de empregos, sendo que os autores propõem analisar a densidade de empregos a partir de dois critérios: as áreas que possuíssem ao menos $1 \%$ do valor total dos empregos considerados; que o valor de empregos por área fosse superior ao valor registrado para toda a região.

O procedimento aqui aplicado é quase similar a este último exposto, com a diferença de que, por haver enorme variação no tamanho dos municípios da Ride-DF, optou-se por analisar a densidade de empregos per capita e não por área. Além disto, o Distrito Federal foi desconsiderado no total, já que é enorme concentrador de empregos e levaria a não caracterização da concentração de empregos em quase nenhum espaço (o que se coaduna com o interesse do trabalho em analisar justamente a densidade nos municípios da Ride-DF - nas tabelas identificados como "Municípios do Entorno"). De forma secundária os dados 
serão analisados em comparação com o Distrito Federal ${ }^{6}$. A partir de tais premissas, os municípios foram classificados como de "alta densidade" de empregos, caso atendessem os dois critérios (detenção de mais de $1 \%$ dos empregos totais e número de empregos per capita maior que os empregos per capita da região considerada); "média densidade", caso atendessem apenas um dos critérios; "baixa densidade", caso não atendessem nenhum dos dois. Os resultados para todos os anos foram, por fim, comparados com a tipologia apresentada na seção anterior.

Os resultados foram ainda comparados com a evolução dos empregos formais nos municípios da Ride-DF, feito a partir dos mesmos dados da RAIS. Tal complementação é necessária tendo em vista a atual situação de crise econômica por que passa o Brasil, podendo revelar, ainda, a influência desta de forma mais clara na concentração ou desconcentração de empregos.

A base de dados utilizadas para tanto foram os dados da RAIS (MINISTÉRIO DO TRABALHO, 2018) para os anos entre 2013 e 2016 e as respetivas populações das Estimativas de População do IBGE (2018).

Como o presente trabalho tem como foco o estudo da densidade de empregos na Ride-DF, optou-se pela não utilização de outros indicadores e medidas próprios da economia regional ligados a tal temática. Um exemplo é o caso do Quociente Locacional (QL), cuja principal contribuição está em apontar possibilidade de especialização de uma determinada área/ cidade em meio à economia de uma região. Tal medida, considerada por Monasterio (2010) como de intuição simples e de fácil aplicação, porém de alcance limitado e cuja interpretação merece maiores cuidados (os resultados podem aparecer distorcidos a depender do grau de detalhamento setorial, por exemplo). Outras medidas próprias da economia regional podem ser alvo de análise em outros trabalhos, dado o interesse muito específico deste na questão da concentração espacial de empregos e em suas metodologias.

\section{Resultados e análise}

Inicialmente, é importante resgatar as informações disponíveis em Souza (2016), que dão a primeira base de comparação dos dados que serão apresentados a seguir. Os cálculos

\footnotetext{
${ }^{6}$ É importante mencionar que o trabalho busca analisar a questão da densidade de empregos e não propriamente a formação de subcentros, que corresponde a uma forma e função do espaço caracterizados por diversas dimensões, demandando outros indicadores para sua identificação.
} 
utilizados naquele trabalho são apresentados na Tabela 1, no qual foram utilizados os dados da RAIS de 2014 e do Censo Demográfico de 2010. A partir da marcação do atendimento dos requisitos postos (tarjas em vermelho), o cálculo apontava como sendo municípios de alta densidade de empregos os seguintes: Abadiânia, Alexânia, Cristalina, Formosa, Luziânia, Pirenópolis, Valparaíso, Buritis e Unaí. Havia, assim, o predomínio de alguns municípios alvo do processo de avanço da agropecuária moderna, casos de Cristalina, Formosa, Luziânia, Buritis e Unaí, além dos dois municípios alcançados pela integração do eixo BrasíliaAnápolis-Goiânia (Abadiânia e Alexânia). Há o caso de Pirenópolis, que se destaca pelo turismo, atividade tendente a criar empregos fixos. Por fim, apenas um município do espaço metropolizado, Valparaíso, apresentava alta densidade de empregos, apontando a tendência de que a expansão metropolitana ainda é concentradora de postos de trabalho no Distrito Federal.

\begin{tabular}{|c|c|c|c|c|}
\hline Município & $\begin{array}{l}\text { Empregos } \\
\text { formais (2014) }\end{array}$ & $\begin{array}{l}\text { População } \\
\text { residente } \\
\text { (2010) }\end{array}$ & $\begin{array}{l}\text { Empregos } \\
\text { formais } \\
\text { per capita }\end{array}$ & $\begin{array}{l}\text { Densidade de } \\
\text { empregos }\end{array}$ \\
\hline Abadiânia - GO & 2.171 & 15.757 & 0,1378 & Alta \\
\hline Água Fria de Goiás - GO & 790 & 5.090 & 0,1552 & Média \\
\hline Águas Lindas de Goiás - GO & 10.845 & 159.378 & 0,0680 & Média \\
\hline Alexânia - GO & 4.329 & 23.814 & 0,1818 & Alta \\
\hline Cabeceiras - GO & 901 & 7.354 & 0,1225 & Média \\
\hline Cidade Ocidental - GO & 3.928 & 55.915 & 0,0702 & Média \\
\hline Cocalzinho de Goiás - GO & 1.484 & 17.407 & 0,0853 & Média \\
\hline Corumbá de Goiás - GO & 1.038 & 10.361 & 0,1002 & Baixa \\
\hline Cristalina - GO & 11.516 & 46.580 & 0,2472 & Alta \\
\hline Formosa - GO & 14.799 & 100.085 & 0,1479 & Alta \\
\hline Luziânia - GO & 22.299 & 174.531 & 0,1278 & Alta \\
\hline Mimoso de Goiás - GO & 400 & 2.685 & 0,1490 & Média \\
\hline Novo Gama - GO & 4.711 & 95.018 & 0,0496 & Média \\
\hline Padre Bernardo - GO & 2.670 & 27.671 & 0,0965 & Média \\
\hline Pirenópolis - GO & 3.814 & 23.006 & 0,1658 & Alta \\
\hline Planaltina - GO & 6.542 & 81.649 & 0,0801 & Média \\
\hline Santo Antônio do Descoberto - GO & 4.723 & 63.248 & 0,0747 & Média \\
\hline Valparaíso - GO & 16.270 & 132.982 & 0,1223 & Alta \\
\hline Vila Boa - GO & 928 & 4.735 & 0,1960 & Média \\
\hline Buritis - MG & 3.515 & 22.737 & 0,1546 & Alta \\
\hline Cabeceira Grande - MG & 791 & 6.453 & 0,1226 & Média \\
\hline Unaí - MG & 17.031 & 77.565 & 0,2196 & Alta \\
\hline Municípios do Entorno & 135.495 & 1.154 .024 & 0,1174 & \\
\hline Brasília - DF & 1.321 .758 & 2.570 .160 & 0,5143 & Centro principal \\
\hline Ride-DF & 1.457 .253 & 3.724 .184 & 0,3913 & \\
\hline
\end{tabular}

Tabela 1 - Cálculo da densidade de empregos nos municípios da Ride-DF utilizado em Souza (2016). 
Na Tabela 2 aparecem, inicialmente, os resultados a partir dos dados para 2013. Neles, apareceram como de alta densidade de empregos os resultados dos municípios Abadiânia, Alexânia, Cristalina, Formosa, Luziânia, Pirenópolis, Buritis e Unaí. Em comparação com os dados da Tabela 1, apenas Valparaíso não consta como sendo de alta densidade de empregos. Quanto aos outros municípios, não se verificam alterações.

\begin{tabular}{|c|c|c|c|c|}
\hline Município & $\begin{array}{l}\text { Empregos formais } \\
\text { (2013) }\end{array}$ & $\begin{array}{l}\text { População } \\
\text { residente } \\
\text { estimada } \\
(2013) \\
\end{array}$ & $\begin{array}{l}\text { Empregos } \\
\text { formais per } \\
\text { capita }\end{array}$ & $\begin{array}{l}\text { Densidade de } \\
\text { empregos }\end{array}$ \\
\hline Abadiânia - GO & 1.956 & 17.326 & 0,1129 & Alta \\
\hline Água Fria de Goiás - GO & 754 & 5.395 & 0,1398 & Média \\
\hline Águas Lindas de Goiás - GO & 9.415 & 177.890 & 0,0529 & Média \\
\hline Alexânia - GO & 4.272 & 25.468 & 0,1677 & Alta \\
\hline Cabeceiras - GO & 861 & 7.717 & 0,1116 & Média \\
\hline Cidade Ocidental - GO & 4.177 & 61.552 & 0,0679 & Média \\
\hline Cocalzinho de Goiás - GO & 1.542 & 18.623 & 0,0828 & Média \\
\hline Corumbá de Goiás - GO & 1.052 & 10.829 & 0,0971 & Baixa \\
\hline Cristalina - GO & 11.333 & 51.149 & 0,2216 & Alta \\
\hline Formosa - GO & 15.317 & 108.503 & 0,1412 & Alta \\
\hline Luziânia - GO & 22.349 & 188.181 & 0,1188 & Alta \\
\hline Mimoso de Goiás - GO & 334 & 2.730 & 0,1223 & Média \\
\hline Novo Gama - GO & 5.189 & 103.085 & 0,0503 & Média \\
\hline Padre Bernardo - GO & 2.598 & 30.059 & 0,0864 & Média \\
\hline Pirenópolis - GO & 3.534 & 24.111 & 0,1466 & Alta \\
\hline Planaltina - GO & 7.566 & 86.014 & 0,0880 & Média \\
\hline Santo Antônio do Descoberto - GO & 5.497 & 67.993 & 0,0808 & Média \\
\hline Valparaíso - GO & 14.964 & 146.694 & 0,1020 & Média \\
\hline Vila Boa - GO & 912 & 5.246 & 0,1738 & Média \\
\hline Buritis - MG & 3.425 & 23.979 & 0,1428 & Alta \\
\hline Cabeceira Grande - MG & 775 & 6.774 & 0,1144 & Média \\
\hline Unaí - MG & 16.677 & 81.693 & 0,2041 & Alta \\
\hline Municípios do Entorno & 134.499 & 1.251.011 & 0,1075 & \\
\hline Brasília - DF & 1.302 .284 & 2.789 .761 & 0,4668 & \\
\hline Total & 1.436 .783 & 4.040 .772 & 0,3556 & \\
\hline
\end{tabular}

Tabela 2 - Cálculo da densidade de empregos nos municípios da Ride-DF em 2013. (Fonte: RAIS, IBGE - dados tratados pelo autor).

Já a Tabela 3 apresenta os dados para 2014, a partir do cálculo da Estimativa de População do IBGE, permitindo uma comparação mais equitativa com a realidade apontada na Tabela 1. Os resultados apontam como sendo de alta densidade de empregos o mesmo grupo de municípios apontados na Tabela 1 (Abadiânia, Alexânia, Cristalina, Formosa, Luziânia, 
Pirenópolis, Valparaíso, Buritis e Unaí). Assim, em que pese a atualização dos dados em relação à Tabela 1, os resultados se mantem os mesmos. Isto aponta para a reduzida alteração no quadro demográfico no período, além de, de certa forma, confirmar a proximidade à realidade dos dados anteriormente tratados

\begin{tabular}{|c|c|c|c|c|}
\hline Município & $\begin{array}{l}\text { Empregos } \\
\text { formais } \\
(2014)\end{array}$ & $\begin{array}{l}\text { População } \\
\text { residente } \\
\text { estimada } \\
(2014)\end{array}$ & $\begin{array}{l}\text { Empregos } \\
\text { formais per } \\
\text { capita }\end{array}$ & $\begin{array}{l}\text { Densidade } \\
\text { de } \\
\text { empregos }\end{array}$ \\
\hline Abadiânia - GO & 2.171 & 17.701 & 0,1226 & Alta \\
\hline Água Fria de Goiás - GO & 790 & 5.451 & 0,1449 & Média \\
\hline Águas Lindas de Goiás - GO & 10.845 & 182.526 & 0,0594 & Média \\
\hline Alexânia - GO & 4.329 & 25.805 & 0,1678 & Alta \\
\hline Cabeceiras - GO & 901 & 7.773 & 0,1159 & Média \\
\hline Cidade Ocidental - GO & 3.928 & 62.903 & 0,0624 & Média \\
\hline Cocalzinho de Goiás - GO & 1.484 & 18.871 & 0,0786 & Média \\
\hline Corumbá de Goiás - GO & 1.038 & 10.896 & 0,0953 & Baixa \\
\hline Cristalina - GO & 11.516 & 52.235 & 0,2205 & Alta \\
\hline Formosa - GO & 14.799 & 110.388 & 0,1341 & Alta \\
\hline Luziânia - GO & 22.299 & 191.139 & 0,1167 & Alta \\
\hline Mimoso de Goiás - GO & 400 & 2.723 & 0,1469 & Média \\
\hline Novo Gama - GO & 4.711 & 104.899 & 0,0449 & Média \\
\hline Padre Bernardo - GO & 2.670 & 30.599 & 0,0873 & Média \\
\hline Pirenópolis - GO & 3.814 & 24.279 & 0,1571 & Alta \\
\hline Planaltina - GO & 6.542 & 86.751 & 0,0754 & Média \\
\hline Santo Antônio do Descoberto - GO & 4.723 & 69.000 & 0,0684 & Média \\
\hline Valparaíso - GO & 16.270 & 150.005 & 0,1085 & Alta \\
\hline Vila Boa - GO & 928 & 5.371 & 0,1728 & Média \\
\hline Buritis - MG & 3.515 & 24.169 & 0,1454 & Alta \\
\hline Cabeceira Grande - MG & 791 & 6.818 & 0,1160 & Média \\
\hline Unaí - MG & 17.031 & 82.298 & 0,2069 & Alta \\
\hline Municípios do Entorno & 135.495 & 1.272 .600 & 0,1065 & \\
\hline Brasília - DF & 1.321 .758 & 2.852 .372 & 0,4634 & \\
\hline Total & 1.457.253 & 4.124.972 & 0,3533 & \\
\hline
\end{tabular}

Tabela 3 - Cálculo da densidade de empregos nos municípios da Ride-DF em 2014. (Fonte: RAIS, IBGE - dados tratados pelo autor).

A Tabela 4 apresenta os dados para o ano de 2015. Novamente, os mesmos municípios (Abadiânia, Alexânia, Cristalina, Formosa, Luziânia, Pirenópolis, Valparaíso, Buritis e Unaí) aparecem com alta densidade de empregos, apontando para pouca mobilidade no quadro geral da densidade de empregos. 


\begin{tabular}{|c|c|c|c|c|}
\hline Município & $\begin{array}{l}\text { Empregos } \\
\text { formais (2015) }\end{array}$ & $\begin{array}{l}\text { População } \\
\text { residente } \\
\text { estimada } \\
\text { (2015) }\end{array}$ & $\begin{array}{l}\text { Empregos } \\
\text { formais per } \\
\text { capita }\end{array}$ & $\begin{array}{l}\text { Densidade } \\
\text { de } \\
\text { empregos }\end{array}$ \\
\hline Abadiânia - GO & 2.342 & 18.069 & 0,1296 & Alta \\
\hline Água Fria de Goiás - GO & 860 & 5.507 & 0,1562 & Média \\
\hline Águas Lindas de Goiás - GO & 11.933 & 187.072 & 0,0638 & Média \\
\hline Alexânia - GO & 4.409 & 26.135 & 0,1687 & Alta \\
\hline Cabeceiras - GO & 925 & 7.829 & 0,1182 & Média \\
\hline Cidade Ocidental - GO & 4.230 & 64.229 & 0,0659 & Média \\
\hline Cocalzinho de Goiás - GO & 1.630 & 19.115 & 0,0853 & Média \\
\hline Corumbá de Goiás - GO & 1.039 & 10.961 & 0,0948 & Baixa \\
\hline Cristalina - GO & 11.880 & 53.300 & 0,2229 & Alta \\
\hline Formosa - GO & 15.560 & 112.236 & 0,1386 & Alta \\
\hline Luziânia - GO & 22.654 & 194.039 & 0,1167 & Alta \\
\hline Mimoso de Goiás - GO & 499 & 2.715 & 0,1838 & Média \\
\hline Novo Gama - GO & 2.909 & 106.677 & 0,0273 & Média \\
\hline Padre Bernardo - GO & 2.965 & 31.129 & 0,0952 & Média \\
\hline Pirenópolis - GO & 3.276 & 24.444 & 0,1340 & Alta \\
\hline Planaltina - GO & 7.129 & 87.474 & 0,0815 & Média \\
\hline Santo Antônio do Descoberto - GO & 4.640 & 69.988 & 0,0663 & Média \\
\hline Valparaíso - GO & 17.394 & 153.255 & 0,1135 & Alta \\
\hline Vila Boa - GO & 795 & 5.495 & 0,1447 & Média \\
\hline Buritis - MG & 3.521 & 24.351 & 0,1446 & Alta \\
\hline Cabeceira Grande - MG & 797 & 6.861 & 0,1162 & Média \\
\hline Unaí - MG & 16.640 & 82.887 & 0,2008 & Alta \\
\hline Municípios do Entorno & 138.027 & 1.293 .768 & 0,1067 & \\
\hline Brasília - DF & 1.263 .872 & 2.914 .830 & 0,4336 & \\
\hline Total & 1.401.899 & 4.208.598 & 0,3331 & \\
\hline
\end{tabular}

Tabela 4 - Cálculo da densidade de empregos nos municípios da Ride-DF em 2015. (Fonte: RAIS, IBGE - dados tratados pelo autor).

Finalmente, a Tabela 5 apresenta os dados para no ano de 2016. Nestes dados, duas alterações podem ser vistas: inicialmente (e assim como no cálculo de 2013), Valparaíso deixa de ter alta densidade de empregos, por não atender ao requisito mínimo de empregos per capita; o município de Vila Boa passa a constar como de "baixa densidade", assim como Corumbá de Goiás (em seu caso, o que sempre o havia mantido na classificação como "média densidade" era o número de empregos formais per capita). Quanto ao restante da tabela, verifica-se a manutenção da classificação nos anos anteriores. 


\begin{tabular}{|c|c|c|c|c|}
\hline Município & $\begin{array}{l}\text { Empregos } \\
\text { formais (2016) }\end{array}$ & $\begin{array}{l}\text { População } \\
\text { residente } \\
\text { estimada } \\
(2016)\end{array}$ & $\begin{array}{l}\text { Empregos } \\
\text { formais per } \\
\text { capita }\end{array}$ & $\begin{array}{l}\text { Densidade } \\
\text { de empregos }\end{array}$ \\
\hline Abadiânia - GO & 2.245 & 18.427 & 0,1218 & Alta \\
\hline Água Fria de Goiás - GO & 805 & 5.560 & 0,1448 & Média \\
\hline Águas Lindas de Goiás - GO & 12.421 & 191.499 & 0,0649 & Média \\
\hline Alexânia - GO & 4.600 & 26.457 & 0,1739 & Alta \\
\hline Cabeceiras - GO & 995 & 7.882 & 0,1262 & Média \\
\hline Cidade Ocidental - GO & 4.185 & 65.520 & 0,0639 & Média \\
\hline Cocalzinho de Goiás - GO & 1.553 & 19.352 & 0,0803 & Média \\
\hline Corumbá de Goiás - GO & 1.053 & 11.024 & 0,0955 & Baixa \\
\hline Cristalina - GO & 13.202 & 54.337 & 0,2430 & Alta \\
\hline Formosa - GO & 15.917 & 114.036 & 0,1396 & Alta \\
\hline Luziânia - GO & 21.682 & 196.864 & 0,1101 & Alta \\
\hline Mimoso de Goiás - GO & 305 & 2.708 & 0,1126 & Média \\
\hline Novo Gama - GO & 4.178 & 108.410 & 0,0385 & Média \\
\hline Padre Bernardo - GO & 2.726 & 31.646 & 0,0861 & Média \\
\hline Pirenópolis - GO & 2.867 & 24.604 & 0,1165 & Alta \\
\hline Planaltina - GO & 7.069 & 88.178 & 0,0802 & Média \\
\hline Santo Antônio do Descoberto - GO & 4.364 & 70.950 & 0,0615 & Média \\
\hline Valparaíso - GO & 15.954 & 156.419 & 0,1020 & Média \\
\hline Vila Boa - GO & 304 & 5.615 & 0,0541 & Baixa \\
\hline Buritis - MG & 3.339 & 24.524 & 0,1362 & Alta \\
\hline Cabeceira Grande - MG & 804 & 6.901 & 0,1165 & Média \\
\hline Unaí - MG & 16.454 & 83.448 & 0,1972 & Alta \\
\hline Municípios do Entorno & 137.022 & 1.314 .361 & 0,1042 & \\
\hline Brasília - DF & 1.250 .750 & 2.977 .216 & 0,4201 & \\
\hline Total & 1.387 .772 & 4.291.577 & 0,3234 & \\
\hline
\end{tabular}

Tabela 5 - Cálculo da densidade de empregos nos municípios da Ride-DF em 2016. (Fonte: RAIS, IBGE - dados tratados pelo autor).

Para facilitar e iniciar a discussão dos resultados, são comparados os resultados para os quatro anos analisados e de acordo com a tipologia mencionada anteriormente (SOUZA, 2016), dado apresentado na Tabela 6. Os resultados apontam para a permanência como "alta densidade de empregos formais" nos quatro anos analisados dos municípios de Abadiânia, Alexânia, Cristalina, Formosa, Luziânia, Pirenópolis, Buritis e Unaí. Já as oscilações ficaram por conta do caso de Valparaíso, que se manteve como de alta densidade apenas nos anos de 2014 e 2015, e Vila Boa que passou a ter baixa densidade no último ano analisado (tendo mantido a classificação de média densidade nos anos anteriores). Os outros municípios mantiveram-se constantes, seja na classificação "média", seja na "baixa" (para este último, apenas Corumbá de Goiás). 


\begin{tabular}{|c|c|c|c|c|c|}
\hline \multirow[t]{2}{*}{ Município } & \multicolumn{4}{|c|}{ Densidade de empregos formais } & \multirow{2}{*}{\begin{tabular}{|l} 
Tipologia do \\
município, segundo \\
Souza (2016)
\end{tabular}} \\
\hline & 2013 & 2014 & 2015 & 2016 & \\
\hline Abadiânia - GO & Alta & Alta & Alta & Alta & \multirow{2}{*}{$\begin{array}{l}\text { Eixo Brasília- } \\
\text { Anápolis-Goiânia }\end{array}$} \\
\hline Alexânia - GO & Alta & Alta & Alta & Alta & \\
\hline Água Fria de Goiás - GO & Média & Média & Média & Média & \multirow{5}{*}{$\begin{array}{l}\text { Agropecuária } \\
\text { tradicional }\end{array}$} \\
\hline Cocalzinho de Goiás - GO & Média & Média & Média & Média & \\
\hline Corumbá de Goiás - GO & Baixa & Baixa & Baixa & Baixa & \\
\hline Mimoso de Goiás - GO & Média & Média & Média & Média & \\
\hline Padre Bernardo - GO & Média & Média & Média & Média & \\
\hline Águas Lindas de Goiás - GO & Média & Média & Média & Média & \multirow{7}{*}{$\begin{array}{l}\text { Centro } \\
\text { metropolitano e } \\
\text { espaço } \\
\text { metropolizado }\end{array}$} \\
\hline Cidade Ocidental - GO & Média & Média & Média & Média & \\
\hline Novo Gama - GO & Média & Média & Média & Média & \\
\hline Planaltina - GO & Média & Média & Média & Média & \\
\hline Santo Antônio do Descoberto - GO & Média & Média & Média & Média & \\
\hline Valparaíso - GO & Média & Alta & Alta & Média & \\
\hline Brasília - DF & - & - & - & - & \\
\hline Cabeceiras - GO & Média & Média & Média & Média & \multirow{7}{*}{$\begin{array}{l}\text { Arco da agropecuária } \\
\text { moderna }\end{array}$} \\
\hline Cristalina - GO & Alta & Alta & Alta & Alta & \\
\hline Formosa - GO & Alta & Alta & Alta & Alta & \\
\hline Vila Boa - GO & Média & Média & Média & Baixa & \\
\hline Buritis - MG & Alta & Alta & Alta & Alta & \\
\hline Cabeceira Grande - MG & Média & Média & Média & Média & \\
\hline Unaí - MG & Alta & Alta & Alta & Alta & \\
\hline Luziânia - GO & Alta & Alta & Alta & Alta & $\begin{array}{l}\text { Área de influências } \\
\text { combinadas }\end{array}$ \\
\hline Pirenópolis - GO & Alta & Alta & Alta & Alta & Área do turismo \\
\hline
\end{tabular}

Tabela 6 - Comparativo dos resultados do cálculo da densidade de empregos nos municípios da Ride-DF entre 2013 e 2016.

Já a comparação dos resultados em relação à tipologia dos municípios da Ride-DF considerada neste trabalho, aponta para o predomínio de municípios de alta densidade de empregos formais nos municípios das sub-regiões "Eixo Brasília-Anápolis-Goiânia" e "Arco da agropecuária moderna". Desta forma, estas sub-regiões apresentam-se como as de economia mais dinâmica no atual cenário da Ride-DF, correspondendo aos espaços mais ligados ao processo de reestruturação produtiva na região. O caso de Luziânia-GO corrobora tal quadro, considerando ter tipologia própria ("Área de influências combinadas") e ter parte significativa de seu espaço ocupado pelas atividades da agropecuária moderna. No caso dos municípios abarcados pela expansão da agropecuária moderna, apenas Cabeceiras, Vila Boa e Cabeceira Grande não apresentam alta de densidade de empregos, sendo 
identificados como os municípios de menor população (e associados mais propriamente à produção que à prestação de serviços à agropecuária moderna, papel cumprido, em maior ou menor grau, pelos outros municípios deste grupo).

O caso de Pirenópolis-GO, que possui tipologia própria ("Área do turismo") aponta para a importância da atividade turística na economia do município, que o manteve com alta densidade de emprego nos quatro anos analisados.

Quanto às outras tipologias, chama a atenção para o resultado dos municípios da sub-região "Centro metropolitano e espaço metropolizado", que abarca Brasília e os municípios atingidos por seu processo de expansão metropolitana. Apenas Valparaíso aparece como de alta densidade de empregos, e apenas nos anos de 2014 e 2015. Ainda que Luziânia, até pela tipologia a ela empregada, também apareça como de alta densidade, o resultado geral aponta para a tendência de reduzida concentração de postos de trabalho nos municípios afetados pela expansão metropolitana, o que revela o lado concentrador da estrutura econômica do processo de metropolização brasiliense.

Em relação aos municípios da sub-região "agropecuária tradicional" não foi registrado nenhum município de alta densidade de empregos, apontando para o menor dinamismo da vida econômica destes municípios, em geral de reduzida população.

Buscando analisar o quadro atual de crise econômica por que passa o Brasil no momento, a Tabela 7 apresenta a variação do emprego formal na Ride-DF, no período entre 2013 e 2016. Os dados estão divididos a partir da tipologia proposta.

Uma forma de analisar tais dados, considerando a questão do interesse no aumento/ redução da concentração de empregos nos municípios pode ser feita a partir da tipologia proposta. Assim, no caso dos municípios do Eixo Brasília-Anápolis-Goiânia, verifica-se oscilação negativa apenas no último período analisado, para o caso de Abadiânia, o que aponta para uma tendência à geração de postos formais de emprego, com alguma estabilidade.

No caso dos municípios da agropecuária tradicional, as oscilações negativas são muito claras no último período, revelando maior fragilidade de suas economias (é emblemático o caso de Mimoso de Goiás, no qual há duas significativas oscilações positivas nos primeiros períodos e a perda de quase todo este saldo positivo na última parcial). Tal resultado é de certa 
forma esperado, tendo em vista tratar-se de municípios pequenos, de menor diversificação produtiva e consequente maior vulnerabilidade a choques externos.

\begin{tabular}{|c|c|c|c|c|}
\hline Município & $\begin{array}{l}\text { Variação } \\
2013- \\
2014 \\
\end{array}$ & $\begin{array}{l}\text { Variação } \\
2014- \\
2015 \\
\end{array}$ & $\begin{array}{l}\text { Variação } \\
2015- \\
2016 \\
\end{array}$ & $\begin{array}{l}\text { Tipologia do } \\
\text { Município, de acordo } \\
\text { com Souza (2016) } \\
\end{array}$ \\
\hline Abadiânia - GO & 10,99 & 7,88 & $-4,14$ & \multirow{2}{*}{$\begin{array}{l}\text { Eixo Brasília-Anápolis } \\
\text { Goiânia }\end{array}$} \\
\hline Alexânia - GO & 1,33 & 1,85 & 4,33 & \\
\hline Água Fria de Goiás - GO & 4,77 & 8,86 & $-6,40$ & \multirow{5}{*}{$\begin{array}{l}\text { Agropecuária } \\
\text { tradicional } \\
\end{array}$} \\
\hline Cocalzinho de Goiás - GO & $-3,76$ & 9,84 & $-4,72$ & \\
\hline Corumbá de Goiás - GO & $-1,33$ & 0,10 & 1,35 & \\
\hline Mimoso de Goiás - GO & 19,76 & 24,75 & $-38,88$ & \\
\hline Padre Bernardo - GO & 2,77 & 11,05 & $-8,06$ & \\
\hline Águas Lindas de Goiás - GO & 15,19 & 10,03 & 4,09 & \multirow{7}{*}{$\begin{array}{l}\text { Centro metropolitano } \\
\text { e espaço } \\
\text { metropolizado } \\
\end{array}$} \\
\hline Cidade Ocidental - GO & $-5,96$ & 7,69 & $-1,06$ & \\
\hline Novo Gama - GO & $-9,21$ & $-38,25$ & 43,62 & \\
\hline Planaltina - GO & $-13,53$ & 8,97 & $-0,84$ & \\
\hline Santo Antônio do Descoberto - GO & $-14,08$ & $-1,76$ & $-5,95$ & \\
\hline Valparaíso - GO & 8,73 & 6,91 & $-8,28$ & \\
\hline Brasília - DF & 1,50 & $-4,38$ & $-1,04$ & \\
\hline Cabeceiras - GO & 4,65 & 2,66 & 7,57 & \multirow{7}{*}{$\begin{array}{l}\text { Arco da agropecuária } \\
\text { moderna }\end{array}$} \\
\hline Cristalina - GO & 1,61 & 3,16 & 11,13 & \\
\hline Formosa - GO & $-3,38$ & 5,14 & 2,29 & \\
\hline Vila Boa - GO & 1,75 & $-14,33$ & $-61,76$ & \\
\hline Buritis - MG & 2,63 & 0,17 & $-5,17$ & \\
\hline Cabeceira Grande - MG & 2,06 & 0,76 & 0,88 & \\
\hline Unaí - MG & 2,12 & $-2,30$ & $-1,12$ & \\
\hline Luziânia - GO & $-0,22$ & 1,59 & $-4,29$ & $\begin{array}{l}\text { Área de influências } \\
\text { combinadas }\end{array}$ \\
\hline Pirenópolis - GO & 7,92 & $-14,11$ & $-12,48$ & Área do turismo \\
\hline
\end{tabular}

Tabela 7 - Variação do emprego formal na Ride-DF, em percentual, entre 2013 e 2016 (Fonte: RAIS dados tratados pelo autor)

Para o caso dos municípios do espaço metropolizado, a análise do período em que a crise se torna mais aguda, entre 2015 e 2016, aponta para oscilações negativas em todos os municípios, com exceção de Novo Gama, que passou por significativo crescimento $(43,62 \%)$. Fica caracterizado o impacto claro da crise na porção territorial que teria, em tese, melhor poder de resposta a tal conjuntura, já que aí se localiza o principal centro de empregos e com natureza de menor vulnerabilidade às crises econômicas (setor público). Uma análise mais ampla demonstra considerável quantidade de oscilações negativas mesmo em períodos anteriores, com destaque para os casos de Santo Antônio do Descoberto (onde houve contínuo déficit de empregos formais) e de Brasília, cujas duas últimas parciais são 
negativas. Valparaíso apresentou significativa oscilação negativa no último período, o que pode explicar o fato de não conseguir sustentar-se como de "alta densidade de empregos", conforme os resultados anteriormente analisados.

No caso dos municípios da agropecuária moderna, as oscilações são, em sua maioria positivas, mesmo no período mais agudo da crise economia (2015-2016). Há aí um destaque negativo para o caso de Vila Boa, com variação negativa de mais de $60 \%$ no último período (acaba por se assemelhar aos municípios da agropecuária tradicional). É percetível que as atividades próprias de uma agropecuária moderna se mantêm resistentes ao cenário de crise, algo que se tem verificado mesmo para outros espaços do país - ainda mais evidente pela contradição entre safras recorde e forte contração econômica ${ }^{7}$.

Luziânia, como caso singular, manteve padrão mais próximo da realidade metropolitana que do analisado para os municípios da agropecuária moderna. Outro caso singular, Pirenópolis, manteve trajetória descendente considerável nos últimos dois períodos analisados.

Assim, de forma geral, os resultados apontam para a manutenção, no tempo, da densidade de empregos na Ride-DF, sem que estes dados apontem um impacto mais claro da crise econômica por que passa o Brasil no momento. A análise complementar realizada a partir dos dados da variação percentual dos empregos nos municípios aponta para uma queda quase generalizada no número de empregos formais no período 2015-2016, com exceção do caso dos municípios da agropecuária moderna. Era de se esperar, assim, que estes pudessem apresentar maiores concentrações de emprego, porém as variações mais positivas ocorreram em Cristalina (11,13\%) - que já possui alta densidade - em Cabeceiras (7,57\%), que possui média densidade e cuja alta não foi suficiente, ainda, para caracterizar tal município como de maior concentração.

Há, assim, a tendência de manutenção de uma maior densidade de empregos nos municípios alvo dos processos relacionados à reestruturação produtiva na região, ao passo que o processo de expansão metropolitana, em contraponto, mantém suas tendências concentradoras de empregos no centro principal e manutenção dos municípios como cidades-dormitório. Mesmo a crise econômica não tem alterado tal situação, ainda que ela

\footnotetext{
${ }^{7}$ Uma possível explicação para tal contradição é a manutenção, mesmo em situação de grave déficit fiscal do Governo Federal, das linhas de crédito para o agronegócio, muito por conta de seu muito eficiente lobby político junto ao Executivo e Legislativo federais.
} 
pareça afetar menos os municípios mais envolvidos com a reestruturação produtiva (caso das tipologias Eixo Brasília-Anápolis-Goiânia e Arco da agropecuária moderna). Uma explicação para tal fato reside ainda na alta concentração geral de empregos na área metropolizada, principalmente Brasília, centro principal, a qual mesmo afetada pela redução no número de postos formais de emprego mantém tendência a possuí-los em quantidade muito superior aos de sua área sob influência mais imediata.

\section{Considerações finais}

Tendo em vista a problemática apontada, em torno do processo de reestruturação produtiva capitalista e seu impacto na estrutura econômica das regiões, o trabalho buscou compreender como uma das variantes desta estrutura - a distribuição/ concentração de empregos - tem ocorrido na Ride-DF, região "oficial" de Brasília, que contem parte de seu espaço de influência. $O$ trabalho buscou apresentar uma atualização dos resultados obtidos por Souza (2016), a partir de dados (secundários) mais recentes, visando analisar a evolução recente de um dos aspetos da economia da região, além de buscar compreender possíveis efeitos da atual crise econômica nesse cenário.

Ao considerar, inicialmente, o processo de produção do espaço da Ride-DF, percebe-se a atuação, no momento de três macroprocessos fundamentais: a expansão metropolitana de Brasília, a expansão da agropecuária moderna e a integração do Eixo Brasília-AnápolisGoiânia. A partir disto, foi aplicada metodologia específica para o cálculo da densidade de empregos, em tipologia gerada a partir da incidência dos três macroprocessos considerados: o centro metropolitano e o espaço metropolizado; o arco da agropecuária moderna, a leste do Distrito Federal; os municípios do Eixo Brasília-Anápolis-Goiânia; o caso singular de Luziânia, considerada Área de Influências Combinadas; os municípios da área de Agropecuária Tradicional; e o caso de Pirenópolis, município da Área do Turismo. Verifica-se que os centros com maior constância em termos de densidade de empregos são aqueles ligados aos macroprocessos considerados resultado da reestruturação produtiva na região: a expansão da agropecuária moderna e a integração do Eixo Brasília-Anápolis-Goiânia. Em contraste, os municípios do espaço metropolizado por Brasília raramente apareceram como 
de alta densidade, com exceção do já mencionado para Valparaíso e do caso de Luziânia, cujo território é alvo da expansão metropolitana (mas não só dela).

De forma a complementar a esta análise, foram ainda expostos os dados da variação do emprego formal nestes municípios, cuja análise mais recente permite analisar eventuais impactos da crise econômica na estrutura da Ride-DF. Os resultados demonstraram ser menor o impacto nos municípios ligados aos dois macroprocessos próprios da reestruturação produtiva (expansão da agropecuária moderna e a integração do eixo Brasília-Anápolis-Goiânia). Em contraste, os municípios dos espaços metropolizados foram mais duramente afetados. Comparando com a evolução dos dados da concentração de empregos, é de se esperar que a continuar tal tendência poderá haver um aumento na concentração nos municípios afetados pelos dois macroprocessos ligados à reestruturação produtiva, que parecem menos afetados (ao menos na presente análise) pela crise - é possível que isto ainda não se mostre nos dados e na metodologia utilizadas pelo peso da quantidade de empregos concentradas em Brasília principalmente. Pelas características da estrutura econômica de Brasília, calcada principalmente no setor público, é possível ainda afirmar que a desconcentração de empregos ocorre mais pelo surgimento de novas atividades em municípios de economias antes pouco desenvolvidas do que propriamente por relocalização das atividades do centro principal. Neste caso em específico, a comparação de Brasília com outras realidade metropolitanas envolve especificidades e semelhanças: é específico para Brasília sua trajetória de metrópole terciária "originária", não tendo passado por desconcentração de atividades produtivas, como no caso de metrópole mais antigas - daí a pouca probabilidade da constituição de uma vasta mancha metropolizada, como no caso de São Paulo analisado por Lencioni (2011); em comum a outras realidade metropolitanas, houve a implantação de atividades "estranhas" à metrópole principal em seu espaço de influência e fora de seu controle imediato, traduzindo isto em maior fragmentação de sua região (o que parece tendência global). Quanto à estrutura resultante, ela parece descrever o futuro de um espaço policêntrico fragmentado, sem a previsão de uma ampla dispersão sem padrão estrutural definido da localização dos empregos, conforme Gordon e Richardson (1996).

Considerando os resultados sobre os três macroprocessos principais de estruturação do espaço da Ride-DF, sobre o espaço metropolizado vê-se a manutenção de Brasília como 
centro principal, com reduzida capacidade de induzir maior dispersão de empregos pelo território. Tal quadro se dá pela rigidez espacial do setor público, que não dá qualquer mostra de alterar seu padrão espacial. A situação de crise atual, porém, tem revelado os limites da excessiva dependência do setor público, devendo o planejamento apontar novos rumos (e concretizá-los, em contradição com o histórico de fracasso das tentativas de alteração da estrutura econômica brasiliense nas escalas metropolitana e regional). Especificamente para o caso dos espaços atingidos pela agropecuária moderna, os resultados podem apontar para uma generalizada desconcentração de empregos, o que não parece ser bem o caso. Há a clara formação das chamadas "cidades do agronegócio" (ELIAS; PEQUENO, 2017), que comandam localmente a produção, ao lado de espaços mais dedicados à produção (municípios de menor porte). Isto reforça alguns dos achados de Souza (2016). No caso do Eixo Brasília-Anápolis-Goiânia, os dois municípios a ele associados (Abadiânia e Alexânia) demonstram ter alta densidade de empregos, o que é revelador também de como a integração das economia das capitais federal e goiana e do polo industrial e logístico de Anápolis, ao longo da BR 060, tem revertido no surgimento de novas atividades e novas plantas produtivas, caso das fábricas cervejeiras (uma em cada um dos municípios).

Os resultados apontam ainda implicações para os processos futuros de planejamento, já que o quadro demonstra maior fragmentação em uma escala metropolitana e regional ampliada, sugerindo pouca articulação dos macroprocessos de expansão metropolitana, de um lado, e expansão da agropecuária moderna e integração do Eixo Brasília-AnápolisGoiânia, do outro. Considerando o atual quadro de ausência de atuação de uma política pública articulada no recorte da Ride-DF, a realidade pouco integrada tende a reforçar (quando não mesmo explicar) a atuação pouco abrangente e excessivamente localista dos governos federal, distrital e dos Estados de Goiás e Minas Gerais (e a consequente baixa efetividade de atuação da Sudeco e do Conselho Administrativo da Ride-DF). Outra das prioridades da atuação futura do planejamento na região precisa ser uma melhor distribuição do emprego no espaço metropolizado (que não sustenta nenhum novo espaço de alta densidade, como visto), buscando reduzir o papel de mera cidade-dormitório de muitos municípios. Por outro lado, a desconcentração proporcionada pelas atividades da agropecuária moderna não necessariamente tem revertido em redução de desigualdades 
socioespaciais, como tem sido a experiência nacional e o caso específico da Ride-DF, analisado em Souza (2017b). Quanto à execução das políticas públicas, o papel do governo federal é ainda o de maior preponderância, devendo este assumir mais claramente a RideDF como espaço prioritário de suas ações (principalmente de articulação e coordenação).

Finalmente, é necessário advertir que os resultados apontam para uma das facetas da caracterização dos subcentros, sem, contudo, abarcá-las por completo. Isto se dá especialmente porque não houve uma análise qualitativa dos empregos gerados, e mesmo a questão da gestão territorial (critério utilizado pelo IBGE) não foi considerado. Entretanto, o método utilizado permite evitar que bruscas oscilações na quantidade de empregos em pequenos municípios influenciam claramente no resultado final, especialmente considerando-se os municípios de alta densidade de empregos. Conforme brevemente mencionado na seção sobre metodologia, o uso de outras medidas próprias da economia e geografia regional não foram empregados por não constituírem o foco do trabalho, o que poderá ser feito em trabalhos futuros.

\section{Referências bibliográficas}

ALLEN, John; MASSEY, Doreen; COCHRANE, Allan. Rethinking the region. Londres: Routledge, 1998.

ARAÚJO SOBRINHO, Fernando. Turismo e dinâmica territorial no eixo Brasília - Goiânia. 447 f. Tese (Doutorado). Universidade Federal de Uberlândia, Uberlândia, 2008.

BOURNE, Larry. Are new urban forms emerging? Empirical tests for canadian urban areas. The canadian geography, vol. 33, no 4, p. 312-328, 1989.

COMPANHIA DE PLANEJAMENTO DO DISTRITO FEDERAL (CODEPLAN). Delimitação do espaço metropolitano de Brasília: estudo preliminar para subsidiar a proposta de criação da Região Metropolitana de Brasília. Brasília: CODEPLAN, 1997.

DARDOT, Pierre; LAVAL, Christian. A nova razão do mundo: ensaio sobre a sociedade neoliberal. São Paulo: Boitempo, 2016.

DUARTE, Carlos Marmolejo; NUÑEZ, Carlos Aguirre; LINEROS, Manuel Ruiz. ¿Hacia un sistema de metrópoles españolas policéntricas?: caracterización de su estrutura metropolitana. In: Anals of 6o International Conference Virtual City and Territory, Cidade do México, 2010. Disponível em: <http://upcommons.upc.edu/bitstream/handle/2099/12731/01 Marmolejo Aguirre Ruiz.pdf>. Visto em janeiro de 2018.

ELIAS, Denise; PEQUENO, Renato. Desigualdades socioespaciais nas cidades do Agronegócio. Revista Brasileira de Estudos Urbanos e Regionais, vol. 9, no 1, p. 25-39, 2007.

FREITAG, Patrícia Batista. A institucionalização do planejamento regional de Brasília: o Fundefe e o Pergeb sob a lógica da metropolização. 156f. Dissertação (Mestrado). Faculdade de Arquitetura e Urbanismo, Universidade de Brasília, Brasília, 2012. 
GARCIA-LÓPEZ, Miquel-Àngel; MUÑIZ, Ivan. Employment decentralisation: Polycentricity or scatteration? The case of Barcelona. Urban Studies, v. 47, n. 14, p. 3035-3056, 2010.

GIULIANO, Genevieve; SMALL, Kenneth. Subcenters in the Los Angeles Region. Regional Science and Urban Economics, vol. 119, 1990.

GORDON, Peter; RICHARDSON, Harry. Beyond polycentricity. The dispersed metropolis, Los Angeles, 19701990. Journal of the American Planning Association, vol. 62, № 3, p. 289-295, 1996.

GRAZIANO DA SILVA, José. A nova dinâmica da agricultura brasileira. Campinas: Unicamp-IE, 1996.

HEINRICHS, Dirk; NUISSL, Henning; RODRÍGUEZ SEEGER, CLAUDIA. Dispersión urbana y nuevos desafíos para la gobernanza (metropolitana) en América Latina: el caso de Santiago de Chile. EURE (Santiago), v. 35, n. 104, p. 29-46, 2009.

INSTITUTO BRASILEIRO DE GEOGRAFIA E ESTATÍSTICA (IBGE). Regiões de influência das cidades - 2007. Rio de Janeiro: IBGE, 2008. Disponível em <http://www.ibge.gov.br/home/geociencias/geografia/regic.shtm>. Visto em janeiro de 2018.

INSTITUTO BRASILEIRO DE GEOGRAFIA E ESTATÍSTICA (IBGE). Estimativas da População. Disponível em: <https://sidra.ibge.gov.br/pesquisa/estimapop/tabelas> . Visto em janeiro de 2018.

LENCIONI, Sandra. A metamorfose de São Paulo: o anúncio de um novo mundo de aglomerações difusas. Revista Paranaense de Desenvolvimento, no 120, p. 133-148, 2011.

McDONALD, John. The identification of urban employment subcenters. Journal of Urban Economics, no 32, p. 242-258, 1987.

MIGNOT, Dominique; AGUILÉRA, Anne. Urban Sprawl, polycentrism and commuting. A comparison of seven French urban areas. Urban Public Economics Review, no 001, p. 93-113, 2004.

MINISTÉRIO DO TRABALHO (MT). Programa de Disseminação das Estatísticas do Trabalho - RAIS. Disponível em: <http://pdet.mte.gov.br/rais?view=default>. Visto em janeiro de 2018.

MIRAGAYA, Júlio. Dinâmica econômica, migrações e integração do território no Centro-Oeste: o impacto do eixo Brasília-Goiânia. Dissertação (Mestrado). Departamento de Geografia, Universidade de Brasília, Brasília, 2003.

MONASTERIO, Leonardo. Indicadores de análise regional e espacial. In: CRUZ, Bruno; FURTADO, Bernardo; MONASTERIO, Leonardo; RODRIGUES JÚNIOR, Waldery (orgs.). Economia regional e urbana: teorias e métodos com ênfase no Brasil. Brasília: IPEA, 2010.

MÜNTER, Angelika. Germany's polycentric metropolitan regions in the world city network. Raumforschung und Raumordnung, v. 69, n. 3, p. 187-200, 2011.

NIGRIELLO, Andreína; PEREIRA, Arnaldo Luís; METRAN, Jeanne. Pontos de articulação. Revista dos transportes públicos, ano 25 (4o trimestre), p. 91-108, 2002.

QUEIROZ, Eduardo. A formação histórica da região do Distrito Federal e Entorno: dos municípios-gênese à presente configuração territorial. 135f. Dissertação (Mestrado) Departamento de Geografia, Universidade de Brasília, Brasília, 2007.

PAVIANI, Aldo. Periferização Urbana. In: PAVIANI, Aldo (org.). Urbanização e Metropolização: a gestão dos conflitos em Brasília. Brasília: EdUnB, Codeplan, 1987.

SANTOS, Milton. A natureza do espaço: técnica e tempo, razão e emoção. São Paulo: EdUSP, 2008 (1996).

SOUZA, Sergio Magno Carvalho de. Reestruturação produtiva, produção de subcentros e desigualdades socioespaciais na Ride-DF. 321f. Tese (Doutorado) - Departamento de Geografia, Universidade de Brasília, Brasília, 2016.

SOUZA, Sergio Magno Carvalho de. Reestruturação produtiva e metropolização na Região Integrada de Desenvolvimento do Distrito Federal e Entorno (Ride-DF). Relativizando a perspectiva da região deprimida e dependente. Revista Política e Planejamento Regional, vol. 3, n. 2, pp. 263-282, 2017a. 
SOUZA, Sergio Magno Carvalho de. Expansão metropolitana, agricultura moderna e desigualdades socioespaciais na Ride-DF. Revista Brasileira de Assuntos Regionais e Urbanos, vol. 3, n. 1, p. 71-94, $2017 \mathrm{~b}$.

SUPERINTENDÊNCIA DO DESENVOLVIMENTO DO CENTRO-OESTE (SUDECO). Municípios Ride-DF. Disponível em <http://www.sudeco.gov.br/web/guest/municipios-ride-df> . Visto em janeiro de 2018.

VELTZ, Pierre. Mondialisation, villes et territoires : l'économie d'archipel. Paris : PUF, 1996. 